\title{
SCIENTIFIC REPORTS

\section{Slow Freezing Versus Vitrification of Mouse Ovaries: from Ex Vivo Analyses to Successful Pregnancies after Auto-Transplantation}

\begin{abstract}
Carmen Terren $^{1}$, Maïté Fransolet ${ }^{1}$, Marie Ancion ${ }^{1}$, Michelle Nisolle ${ }^{1,2}$ \& Carine Munaut $^{1 *}$
Slow freezing (SF) is the reference method for ovarian tissue cryopreservation. Vitrification (VT) constitutes an alternative but controversial method. This study compares SF and VT (open [VTo] and closed [VTc] systems) in terms of freezing damage and fertility restoration ability. In vitro analyses of C57BI/6 SF or VTo-ovaries, immediately after thawing/warming or after culture (cult), revealed that event though follicular density was similar between all groups, nuclear density was decreased in VToovaries compared to CT-ovaries $(C T=0.50 \pm 0.012, S F=0.41 \pm 0.03$ and $V T o=0.29 \pm 0.044, p<0.01)$. Apoptosis was higher in VTo-cult ovaries compared to SF-cult ovaries $(p<0.001)$ whereas follicular Bmp15 and Amh gene expression levels were decreased in the ovaries after culture, mostly after VTo $(p<0.001)$. Natural mating after auto-transplantation of SF, VTo and VTc-ovaries revealed that most mice recovered their oestrous cycle. Fertility was only restored with SF and VTo ovaries (SF: 68\%; VTo: 63\%; VTc: $0 \%$; $\mathrm{p}<0.001$ ). Mice auto-transplanted with SF and VTo-ovaries achieved the highest number of pregnancies. In conclusion, in vitro, no differences between SF and VTo were evident immediately after thawing/warming but VTo ovaries displayed alterations in apoptosis and follicular specific proteins after culture. In vivo, SF and VTo ovary auto-transplantation fully restored fertility whereas with VTcovary auto-transplantation no pregnancies were achieved.
\end{abstract}

In recent decades, considerable therapeutic advances have allowed notable improvements in the survival of cancer patients. It becomes imperative to consider the long-term quality of life of survivors. One critical issue among reproductive-aged cancer survivors is the ability to have biological children. Unfortunately, cancer therapies (radiotherapy and/or chemotherapy) increase the risk of infertility and ovarian failure in very young children. Similar concerns have been raised by young adult women who underwent identical treatments ${ }^{1}$. Thus, the treatments of these patients can lead to premature menopause and, consequently, infertility. The limited options available for fertility preservation include cryopreservation of ovarian cortical tissue containing immature primordial follicles followed by auto-transplantation (OCTP $)^{2,3}$. More importantly, OCTP is the only option available for prepubertal patients, female patients requiring urgent therapy for aggressive malignancies and those suffering from hormone-sensitive malignancies ${ }^{4}$. Different studies have demonstrated the resumption of ovarian function even after transplantation of the prepubertal ovarian $\operatorname{cortex}^{5-8}$. To date, more than 130 live births after OCTP have been reported worldwide, with a pregnancy and live birth rate of $33 \%$ and $25 \%$, respectively $4,9,10$

Currently, slow freezing (SF) is the conventional technique used for cryopreservation of the human cortex ${ }^{11}$. Thawing and auto-transplantation are often performed several years later when the patient is cured of her cancer, when she wants to become pregnant and when ovarian failure is observed. Most live births after ovarian cryopreservation have been achieved after SF. However, two successful deliveries have been reported after vitrification $(\mathrm{VT})^{12}$ and two after VT followed by in vitro activation of the human ovarian cortex (IVA-OCTP) ${ }^{13,14}$. VT offers the advantages of time efficiency, with no specific or expensive equipment required and, more importantly, no formation of harmful ice crystals. However, VT requires high concentrations of cryoprotectants compared to SF, which carries a risk for cellular toxicity and osmotic trauma ${ }^{15-17}$. VT has gained wide acceptance as the preferred cryopreservation method for oocytes and embryos ${ }^{18,19}$ and could be a potential alternative to SF for ovarian

${ }^{1}$ Laboratory of Tumor and Development Biology, GIGA-Cancer, University of Liège, Tour de Pathologie (B23), Sart Tilman, B-4000, Liège, Belgium. '2Department of Obstetrics and Gynecology, Hôpital de la Citadelle, University of Liège, B-4000, Liège, Belgium. *email: c.munaut@uliege.be 
tissue. Several previous studies with human ovarian cortex tissue have shown that VT has no effect on the induction of either the apoptotic process or the follicular pool and increases the preservation of ovarian stroma after thawing ${ }^{15,20-22}$. However, these encouraging results were mostly obtained after tissue analysis immediately after the thawing/warming process. Only a limited number of studies have evaluated ovarian tissue survival after VT and transplantation ${ }^{23,24}$, indicating that additional analyses still need to be performed to confirm the safety and relevance of the VT method before proposing it in clinical practice. However, the number of studies is limited, and direct comparisons between them are difficult or impossible because the methods, the compositions of the cryopreservation solutions and the downstream analysis are completely different. Recently, Lee et al. performed a comparison between SF and VT for human ovarian tissue cryopreservation and transplantation onto the back muscle of ovariectomized female SCID mice ${ }^{25}$. Their results indicate that SF is superior to VT in terms of follicle survival and growth after transplantation.

Another critical concern is the biosafety issues of cryopreservation. Currently, procedures are categorized into two types, namely, "open" and "closed" systems, depending on whether there is direct contact with liquid nitrogen $\left(\mathrm{LN}_{2}\right)$. While the open system enables extremely high cooling rates, the direct contact with $\mathrm{LN}_{2}$ increases potential cross-contamination risks ${ }^{26,27}$. To address these safety considerations, closed systems were developed, first and mainly for oocyte and embryo cryopreservation ${ }^{28,29}$, and are currently the only ones used in laboratories.

The first aim of our study was to investigate the effect of the cryopreservation method (SF and VT) on the ability of murine ovaries to support folliculogenesis after thawing/warming. Possible cryoinjuries were assessed by performing histological, immunohistochemical and molecular analyses of control (CT), SF and VTo ovaries before and after in vitro culture. Apoptosis, cell proliferation, follicular density and the expression of a variety of genes specific to follicular integrity, health, and viability were evaluated.

The second aim was to analyse the resumption of ovarian and reproductive functions in vivo after cryopreservation and auto-transplantation of ovaries into mice with ovarian failure.

\section{Materials and Methods}

Collection and preparation of ovaries for in vitro studies. $\mathrm{C} 57 \mathrm{Bl} / 6$ mice $(n=82,4$ weeks old $)$ were obtained from Charles River Laboratories (USA). The ovaries were removed through small dorsolateral skin incisions and were placed either in Leibovitz L-15 medium (Lonza, Verviers, Belgium) supplemented with 10\% Fetal Bovine Serum (FBS; Thermo Fisher Scientific, Gibco, Waltham, Mass., USA) (transport solution for slow freezing (SF)) or in Dulbecco's phosphate-buffered solution (DPBS; Thermo Fisher Scientific, Gibco, Waltham, Mass., USA) supplemented with 20\% FBS (transport solution for vitrification (VT)). Leibovitz L-15 is the conventional medium for the SF procedure, whereas there is no consensus for ovarian tissue VT. Therefore, we used Youm's VT procedure ${ }^{30}$. In order to cryopreserve only the ovary, adjacent tissues taken at the time of ovariectomy were removed under a binocular using a scalpel. The Animal Ethics Committee of the University of Liège approved this study (\# 1547) and all experiments were performed in accordance with relevant guidelines and regulations.

Slow freezing (SF) and thawing procedure. Ovaries were placed in cryopreservative medium containing Leibovitz L-15 medium supplemented with 10\% FBS, 10\% dimethylsulfoxide (DMSO; Merck, Darmstadt, Germany) and $0.1 \mathrm{M}$ sucrose. After equilibration in cryopreservation medium for $30 \mathrm{~min}$ at $4{ }^{\circ} \mathrm{C}$, ovaries were placed in cryovial tubes (Simport, Montreal, Quebec, Canada) and subsequently cooled in a programmable freezer (CL-8800i System; CryoLogic, Mulgrave, Victoria, Australia) as described previously ${ }^{31}$ and stored in liquid nitrogen.

For thawing, cryovials were incubated at room temperature for $2 \mathrm{~min}$ and thawed by rapid immersion at $37^{\circ} \mathrm{C}$ in a water bath. To remove cryoprotectants, ovaries were washed three times for $5 \mathrm{~min}$ at $37^{\circ} \mathrm{C}$ in Leibovitz L- 15 medium.

Vitrification (VT) and warming procedure. Ovaries were placed in DPBS supplemented with $20 \%$ FBS (transport medium). The vitrification procedure is composed of a two-step protocol with ascending concentrations of ethylene glycol (EG) and DMSO in basic transport solution. Ovaries were first incubated in 7.5\% EG and $7.5 \%$ DMSO for $10 \mathrm{~min}$ then $20 \% \mathrm{EG}, 20 \% \mathrm{DMSO}$ and $0.5 \mathrm{M}$ sucrose for $5 \mathrm{~min}$ as described by Youm et al..$^{30}$. All steps of vitrification were carried out on ice ${ }^{32}$ The ovaries were either directly immersed in liquid nitrogen before being transferred in cryotubes (Sarstedt, Nümbrecht, Germany), previously immersed in liquid nitrogen (open method) or placed in a high security freezing straw (closed method) (Cryo Bio System, L'Aigle, France).

For warming, to limit osmotic shock, ovaries were soaked for 5 minutes at $37^{\circ} \mathrm{C}$ in solutions with decreasing concentrations of sucrose $(1,0.5,0.25$ and $0 \mathrm{M}$ sucrose in DPBS-20\% FBS).

In vitro culture. After thawing/warming, some ovaries were cultured for 4 hours at $37^{\circ} \mathrm{C}$ in 96 -well plates (see Table S1 for the experimental distribution). Culture medium was composed of Dulbecco's Modified Eagle Medium (Thermo Fisher Scientific, Gibco, Waltham, MA, USA) supplemented with 10\% decomplemented and desteroidized FBS, 200mM L-Glutamine (Thermo Fisher Scientific, Gibco, Waltham, MA, USA), 1\% of a mixture of insulin $(1000 \mathrm{mg} / \mathrm{l})$, transferrin $(550 \mathrm{mg} / \mathrm{l})$ and selenium $(0.67 \mathrm{mg} / \mathrm{l})$ (Thermo Fisher Scientific, Gibco, Waltham, MA, USA), $1 \mu \mathrm{l} / \mathrm{ml}$ penicillin-streptomycin (Thermo Fisher Scientific Gibco 15140-122 Waltham, MA, USA), $100 \mu \mathrm{g} / \mathrm{ml}$ ascorbic acid (Sigma-Aldrich, St. Louis, MO, USA) and $0.2 \%$ human FSH (Sigma-Aldrich, St. Louis, MO, USA).

Histological assessment. Ovaries fixed in $4 \%$ formaldehyde were paraffin-embedded and serially sectioned ( $5 \mu \mathrm{m}$ sections). Haematoxylin and eosin (H\&E) staining was used for differential follicle counts. The scanned H\&E sections were analysed using NDP view software (NDP.view2 Viewing software U12388-01, Hamamatsu Photonics K.K., Japan). Sections were analyzed by light microscopy for the presence of primordial, 


\begin{tabular}{|c|c|c|c|}
\hline Gene & Primer sequences & $\begin{array}{l}\text { Product } \\
\text { size (bp) }\end{array}$ & UPL Probe (Roche) \\
\hline \multirow{2}{*}{ Amh } & F: 5'-GGG-GAG-ACT-GGA-GAA-CAG-C-3' & \multirow{2}{*}{67} & \multirow{2}{*}{41 (ref: 4688007001) } \\
\hline & R: 5'-AGA-GCT-CGG-GCT-CCC-ATA-3' & & \\
\hline \multirow{2}{*}{ Bax } & F: 5'-AGT-GTC-TCC-GGC-GAA-TTG-3' & \multirow{2}{*}{69} & \multirow{2}{*}{56 (ref: 4688538001 ) } \\
\hline & R: 5'-CCA-CGT-CAG-CAA-TCA-TCC-T-3' & & \\
\hline \multirow{2}{*}{ Bcl-XL } & F: 5'-TGA-CCA-CCT-AGA-GCC-TTG-GA-3' & \multirow{2}{*}{78} & \multirow{2}{*}{2 (ref: 4684982001$)$} \\
\hline & R: 5'-GCT-GCA-TTG-TTC-CCG-TAG-A-3' & & \\
\hline \multirow{2}{*}{ Becn1 } & F: 5'-GAC-TCG-ATT-TTG-TCT-TCC-GTA-CA-3' & \multirow{2}{*}{94} & \multirow{2}{*}{16 (ref: 4686896001 ) } \\
\hline & R: 5'-CTG-GGT-TTT-GAT-GGA-ATA-GGA-G-3' & & \\
\hline \multirow{2}{*}{ Bmp15 } & F: 5'-CAG-TAA-GGC-CTC-CCA-GAG-GT-3' & \multirow{2}{*}{113} & \multirow{2}{*}{21 (ref: 4686942001$)$} \\
\hline & R: 5'-AAG-TTG-ATG-GCG-GTA-AAC-CA-3' & & \\
\hline \multirow{2}{*}{ Gdf 9} & F: 5'-TTC-GTG-TGT-GCC-GGG-CAA-GT-3' & \multirow{2}{*}{196} & \multirow{2}{*}{ SYBR Green } \\
\hline & R: 5'-GTC-ACA-GGA-AGC-TCT-CTG-CCC-A-3' & & \\
\hline \multirow{2}{*}{ Gapdh } & F: 5'-TGT-CCG-TCG-TGG-ATC-TGA-C-3' & \multirow{2}{*}{151} & \multirow{2}{*}{80 (ref: 4689038001$)$} \\
\hline & R: 5'-GAG-TTG-CTG-TTG-AAG-TCG-CA-3' & & \\
\hline
\end{tabular}

Table 1. Primer sequences and product size for RT-qPCR analysis.

primary, secondary and antral follicles based on morphological classification of mouse follicles ${ }^{33}$. The follicular densities (number $/ \mathrm{mm}^{2}$ ) were calculated after manually outlining the ovarian surface (NDP view software).

Ovarian viability was evaluated by nucleus count after haematoxylin staining by computer-assisted image analysis. Using Photoshop CS4 software (Adobe Systems Incorporated, San Jose, CA, USA), a mask was created to delineate the area to be analysed. The number of cells labelled per $\mathrm{mm}^{2}$ was then quantified using MATLAB 9.0.0.341360 (R2016a) software (MathWorks, Inc.).

Apoptosis and cell proliferation in the ovaries were evidenced by immunostaining of caspase- 3 and Ki67, respectively. Sections were deparaffinised and rehydrated, and endogenous peroxidase activity was blocked by incubating the sections in 3\% hydrogen peroxide for $20 \mathrm{~min}$ at room temperature (RT). Nonspecific binding sites were blocked by incubation with phosphate-buffered saline (PBS) containing 10\% bovine serum albumin (BSA) or with serum of the species from which the secondary antibody comes from, for $1 \mathrm{~h}$ at RT. Ki67 primary antibody (Abcam, Cambridge, UK) was diluted 1/100 in PBS-BSA $1 \%$ and incubated for $1 \mathrm{~h}$ at RT. Anti-cleaved caspase-3 antibody (Cell Signaling, Danvers, USA) was diluted 1/300 in the REAL antibody diluent (Dako, Glostrup, Denmark) and incubated overnight at $4{ }^{\circ} \mathrm{C}$, followed by incubation with the secondary antibody HRP linked (ENVISION/HRP ready to use, Dako, Glostrup, Denmark) for $30 \mathrm{~min}$ at RT. The reaction was revealed using $\mathrm{DAB}+($ Dako, Glostrup, Denmark) and the sections were counterstained with haematoxylin.

For the quantitative analysis of immunostaining of caspase-3, labelled follicles were manually counted. Follicles were considered to be labelled when there were more than $30 \%$ of labelled cells within a follicle.

Cell proliferation was determined by computer-assisted image analysis on Ki67-labelled sections. Using Photoshop CS4 software, a mask was created to delineate the area to be analysed. The number of cells labelled per $\mathrm{mm}^{2}$ was then quantified using MATLAB software.

RT real-time-PCR for mRNA quantification. Total RNA from ovaries was extracted using the RNeasy Mini Kit (Qiagen, Valencia, CA, USA), following the manufacturers protocol. $900 \mathrm{ng}$ of RNA was then reverse transcribed into cDNA using the Transcriptor First Strand cDNA Synthesis Kit (Roche, Basel, Switzerland). Real-time quantitative PCR were performed using specific primers and either Brilliant SYBR GREEN qPCR master mix (Roche, Basel, Switzerland) or FastStart Essential DNA Probes Master (Roche, Basel, Switzerland) and a specific probe (Universal Probe Library, Roche, Basel, Switzerland) on a LightCycler ${ }^{\circledR} 480$ (Roche, Basel, Switzerland). Primer sequences for the target genes and corresponding probes are summarized in Table 1 . Gene expression values were normalized to a housekeeping gene (Gapdh), and mRNA expression levels were quantified using the $\triangle \mathrm{CT}$ method.

Western blot analysis. Two ovaries were pooled by condition to obtain a sufficient protein concentration. The protein extraction was carried out with $175 \mu$ l of radio immunoprecipitation assay (RIPA) buffer containing $4 \%$ of a protease inhibitor (Roche, Basel, Switzerland). Lysate were collected and protein concentrations determined using a protein assay kit (Bio-Rad Laboratories, Hercules, CA, USA). Equal amounts of protein were denatured and separated by electrophoresis on 15\% SDS-polyacrylamide gels and then transferred onto a polyvinylidene difluoride membrane (PerkinElmer, Waltham, MA, USA) at $100 \mathrm{~V}$ for $1 \mathrm{~h}$. After blocking, proteins were incubated with respective primary antibodies in blocking solution according to the manufacturer's protocol (Table 2). The appropriate horseradish peroxidase-conjugated secondary antibody was added to the membrane followed by a $1 \mathrm{~h}$ incubation at RT. After sequential washing of the membranes to remove excess secondary antibody, signals were detected using an enhanced chemiluminescence (ECL) kit (PerkinElmer, Waltham, MA, USA) according to the manufacturer's instructions in a LAS4000 imager (Fujifilm, Tokyo, Japan).

Mice model of induced ovarian failure. A unilateral ovariectomy was performed on 8-week-old $\mathrm{C} 57 \mathrm{Bl} / 6$ mice. After one week, mice were daily intraperitoneally treated with vinylcyclohexene dioxide (VCD, Sigma-Aldrich, St. Louis, MO, USA) for 19 days $(100 \mu \mathrm{l} / \mathrm{mouse}$ at $160 \mathrm{mg} / \mathrm{kg}$ of VCD diluted in sesame oil) to 


\begin{tabular}{|l|l|l|l|}
\hline $\begin{array}{l}\text { Target } \\
\text { Protein }\end{array}$ & $\begin{array}{l}\text { Blocking } \\
\text { Solution }\end{array}$ & Primary Antibody & Secondary Antibody \\
\hline BMP15 & Milk 5\% & $\begin{array}{l}\text { Rabbit monoclonal antibody (Abcam, } \\
\text { Cambridge, UK) 1:2000 }\end{array}$ & $\begin{array}{l}\text { Goat anti-rabbit HRP-linked antibody } \\
\text { (Cell signalling, Danvers, USA) 1:2000 }\end{array}$ \\
\hline CASPASE-3 & Milk 5\% & $\begin{array}{l}\text { Rabbit monoclonal antibody (Cell } \\
\text { signalling, Danvers, USA) 1:1000 }\end{array}$ & $\begin{array}{l}\text { Goat anti-rabbit HRP-linked antibody } \\
\text { (Cell signalling, Danvers, USA) 1:2000 }\end{array}$ \\
\hline LC3 & Casein & $\begin{array}{l}\text { Mouse Monoclonal antibody (Nanotools, } \\
\text { Teningen, Germany) 1:1000 }\end{array}$ & $\begin{array}{l}\text { Horse anti-mouse HRP-linked antibody } \\
\text { (Cell signalling, Danvers, USA) 1:2000 }\end{array}$ \\
\hline
\end{tabular}

Table 2. Antibodies used for Western blot analysis.

induce ovarian failure ${ }^{34}$. Mice in the control group $(n=5)$ were treated with the vehicle. Two months after the last VCD injection, the status of oestrous cycle was determined by daily vaginal cytology ${ }^{35}$. The onset and cessation of cyclicity were determined by the cell population in the vaginal lavage. Mice were considered to be in menopause after 2 weeks of consecutive dioestrous. Mice in the control group kept their cyclicity (Fig. S2).

Auto-transplantation. After confirmation of menopause, cryopreserved-thawed/warmed ovaries were auto-transplanted. Briefly, the remaining non-functional ovary was externalized under gas anaesthesia (Isoflurane, Dechra, Northwich, UK). Under a binocular, using thin spring scissors, a small incision was made at the level of the ovarian bursa. The frozen-thawed/warmed ovary was then slipped through this incision into the ovarian bursa that still contains the non-functional ovary. The ovaries were then gently placed back into the peritoneal cavity before closing the peritoneum and the skin. Sham operation was performed in the control group.

After the auto-transplantation, daily vaginal smears were performed to detect a possible resumption of ovarian cycles. The auto-transplanted female mice which had recovered an estrous cycle after surgery as well as control mice (unilaterally ovariectomized and sham operated) were paired with male C57Bl/6 with proven mating abilities (one male for 2-3 females). Once pregnancy was confirmed either by visualization of a vaginal plug or by increasing weight, the females were housed individually. If no vaginal plug was detected, pairing was continued up to 18 weeks. The number of females that gave birth and of pups born alive was recorded. The experimental design is reported in a flow chart (Supplemental, Fig. S2).

Statistical analysis. Statistical analyses were performed using GraphPad Prism software (GraphPad, San Diego, CA, USA). All data are presented as means \pm SEM. Nonparametric Kruskal-Wallis test followed by multiple comparison Dunn's post-test was applied for multigroup comparisons. The comparison between the two freezing techniques on the fecundity of females after auto-transplantation and natural mating was carried out by Chi-Square statistical test. A probability of $\mathrm{p}<0.05$ was considered to be statistically significant.

\section{Results}

In vitro study: Influence of the cryopreservation method. Histological evaluation and follicular counts. The experimental design is summarized in Fig. 1. Morphological analyses of the ovaries revealed that the morphology of SF ovaries was similar to that of CT ovaries. Follicular integrity and stromal structures were better preserved after SF than after VTo (Fig. 2). The stromal density decreased in both cryopreserved groups of ovaries. The density of the granulosa cells associated with growing follicles was higher after SF than after VTo (Fig. 2b,c). However, in all groups, the primordial follicles displayed ]a healthy appearance (Fig. 2a-c). After $4 \mathrm{~h}$ in culture, the prevalence of stromal cell damage increased in all groups, accompanied by cell losses, with VTo ovaries being the most affected (Fig. 2d-f). The nuclear density evaluated after haematoxylin staining and computer-assisted quantification was decreased in VTo ovaries compared to CT ovaries (CT $=0.50 \pm 0.012, \mathrm{SF}=0.41 \pm 0.03$ and $\mathrm{VTo}=0.29 \pm 0.044$, mean $\pm \mathrm{SEM}, \mathrm{p}<0.01)$. After $4 \mathrm{~h}$ of culture, there were no additional differences between the groups (Fig. $2 \mathrm{~g}$ ). The follicular count according to follicle maturation was evaluated next. There were no differences in the follicular densities of the primordial follicles between groups either after thawing/warming or after $4 \mathrm{~h}$ of culture (Fig. 3a). The mean primary or growing follicle density was similar between all groups (Fig. 3b,c).

Cell proliferation. The health and proliferative status of the stroma and granulosa cells were assessed by Ki67 immunostaining of ovarian sections. As expected, in the CT ovaries, the immunolabelling of the granulosa cells was strong, while the stroma was totally devoid of Ki67 staining (Fig. 4a-f). After cryopreservation and in vitro culture, proliferation decreased in all cases compared to that in the CT or CT-cult ovaries (Fig. 4g).

Follicular integrity and functionality. To assess apoptosis, immunohistochemistry for active caspase-3 (CASP3) was performed on ovarian sections. In all sections, active caspase- 3 was only found in secondary or more mature follicles (Fig. 5a-f). In CT ovaries, almost no staining was observed (Fig. 5a). After quantification (Fig. 5g) of follicles with a staining coverage of more (Fig. 5h) or less (Fig. 5i) than 30\%, a trend towards an increase in cell death was observed after both cryopreservation methods $(1.9 \pm 1.9$ in SF, $4.9 \pm 1.8$ in VTo versus $0.2 \pm 0.2$ in $\mathrm{CT}$, mean \pm SEM) (Fig. $5 \mathrm{j}$ ). A further increase in active CASP3 was observed in all groups after $4 \mathrm{~h}$ of in vitro culture, with the CT ovaries being the most affected (Fig. 5d-f). The SF-cult ovaries displayed a lower level of active caspase-3 than the CT-cult ovaries (9.4 \pm 4.0 in SF-cult, $14 \pm 8.3$ in VTo-cult versus $28.2 \pm 2.9$ in CT-cult, mean \pm SEM, $p<0.05$ ) (Fig. 5j). Western blot analysis confirmed the increase in cleaved caspase- 3 after cryopreservation ( $\mathrm{p}<0.01$, Figs. $5 \mathrm{~m}$ and S1a). RT-qPCR analysis was performed to evaluate the $\mathrm{Bax} / \mathrm{Bcl}$ - $x \mathrm{l}$ mRNA ratios to assess susceptibility to apoptosis and to evaluate Becn 1 mRNA levels as a marker of autophagy. Cryopreservation by SF or VTo did not affect the $B a x / B c l-x l$ ratio or the Becn 1 mRNA level in the different groups of ovaries. 


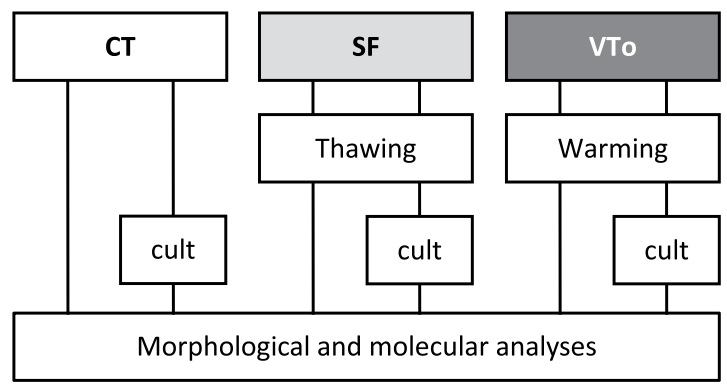

Figure 1. Experimental design for in vitro analysis. Morphological and molecular analyses of follicular density, apoptosis and follicular specific genes expression (immunohistochemistry, western-blot, RT-qPCR) in slow frozen/thawed and vitrified/warmed ovaries were done in parallel and compared to fresh control ovaries. CT: control/fresh ovaries; SF: slow frozen/thawed ovaries, VTo: open vitrified/warmed ovaries, cult: ex vivo culture during 4 hours.

After $4 \mathrm{~h}$ in culture, the $\mathrm{Bax} / \mathrm{Bcl}-\mathrm{xl}$ ratios increased in all groups, with VTo-cult ovaries being the most affected $(\mathrm{p}<0.001$, Fig. $5 \mathrm{k})$. Conversely, a tendency towards a decrease in Becn1 mRNA was observed in all groups of cultured ovaries compared to the results obtained after cryopreservation (Fig. 5l). Western blot analysis of LC3 protein also confirmed the decreasing trends in culture in all conditions after $4 \mathrm{~h}$ (Figs. 5n and S1b).

RT-qPCR analysis of the mRNA levels of $G d f 9$, a gene required for ovarian folliculogenesis, revealed no difference between SF or VTo ovaries compared to CT ovaries. No further difference in Gdf9 mRNA was observed after in vitro culture for $4 \mathrm{~h}$ for either cryopreservation method (Fig. 6a). The Bmp15 and Amh mRNA levels were similar between the CT, SF and VTo ovaries. After $4 \mathrm{~h}$ in culture, the Bmp15 and Amh mRNA levels decreased in all groups, with the most notable decrease in the VTo-cult ovaries $(\mathrm{p}<0.001$, Fig. $6 \mathrm{~b}, \mathrm{c})$. Western blot analysis of BMP15 protein confirmed the RT-qPCR results (Figs. 6d and S1c).

In vivo study: Comparison of the SF and VT methods. The experimental design for this portion of the study is summarized in Fig. S2 (Supplemental data). Mice were randomly assigned to an experimental group, and unilaterally removed ovaries were treated accordingly $(C T, n=5 ; S F, n=22$; VTo with open system, $n=11$; and VTc with closed system, $\mathrm{n}=11$ ). Vaginal cytology analysis was performed from the eighth week after the first injection of VCD, and oestrous cyclicity was absent in approximately $75 \%$ of all mice. Ovarian failure was complete in all mice within the subsequent 3 weeks (Fig. S3). Auto-transplantation of the cryopreserved ovaries into the remaining bursa of the follicle-depleted non-functional ovary was performed. Vaginal cytology analysis of the auto-transplanted mice showed that one week later, some mice had already recovered their oestrous cyclicity. Most mice resumed their ovarian cycles 3 weeks after auto-transplantation (SF: 95\%; VTo: 91\%; VTc: 82\%) (Table 3). There was no significant difference in the time required for the recovery of the oestrous cycle between the groups of females receiving SF, VTo or VTc ovaries. All females with recovered oestrous cycles were naturally mated, and their fecundity was assessed. Table 3 summarizes the fecundity of the grafted mice examined by natural mating after transplantation (associated statistical analyses are presented as Supplemental data (Table S2)). Twenty weeks after auto-transplantation, all mice in the CT group had become pregnant, and most of them gave birth to viable pups. More than $60 \%$ of the mice auto-transplanted with SF or VTo ovaries were pregnant 20 weeks after auto-transplantation and delivered pups. In contrast, mice with VTc-auto-transplanted ovaries never became pregnant $(\mathrm{p}<0.001)$.

The number of pregnancies among all groups was significantly different $(\mathrm{p}=0.0005)$. In both the CT and SF-ovary auto-transplantation groups, the female mice delivered more than once, with no differences between these 2 groups. The delivery rate was also similar for mice with VTo ovaries than for those with SF ovaries. The VTo mice mostly delivered only once. The mean litter sizes of the CT and SF groups were similar but tended to be lower in the VTo group (CT: $3.75 \pm 0.59$, SF: $3.7 \pm 0.51$, VTo: $2.8 \pm 0.86$, mean \pm SEM). However, in all groups, several litters did not survive. This was most apparent in the VTo group, in which only one litter survived. Among pups that were not victims of maternal cannibalism, all showed normal further development.

All females were sacrificed 8 months after unilateral ovariectomy, and ovaries were histologically examined after haematoxylin \& eosin staining. Both normal follicular development and corpora lutea formation were observed in the CT group and SF-graft ovary group of previously pregnant mice (Fig. 7a,b), whereas in the VTo graft ovary group, mostly corpora lutea were found (Fig. 7d). When the SF grafts from the mice that never became pregnant were analysed, no more resting or developing follicles were detected (Fig. 7c).

\section{Discussion}

Ovarian tissue cryopreservation aims to increase the chances of prospective fertility in cancer patients after treatment by means of transplantation. Currently, SF is considered the "gold standard" for ovarian tissue cryopreservation, and most of the reported live births after auto-transplantation have been achieved with this method $^{4}$. Additionally, VT has recently been used ${ }^{36,37}$. By itself, cryopreservation of single cells, such as oocytes, is already challenging, but cryopreservation has become more complicated for complex organs composed of heterogeneous cell types, such as the ovary. Indeed, each cell type has its own requirements for preservation. These requirements can be so different among different cell types that it can become impossible to develop an optimized cryopreservation protocol $^{38,39}$. 

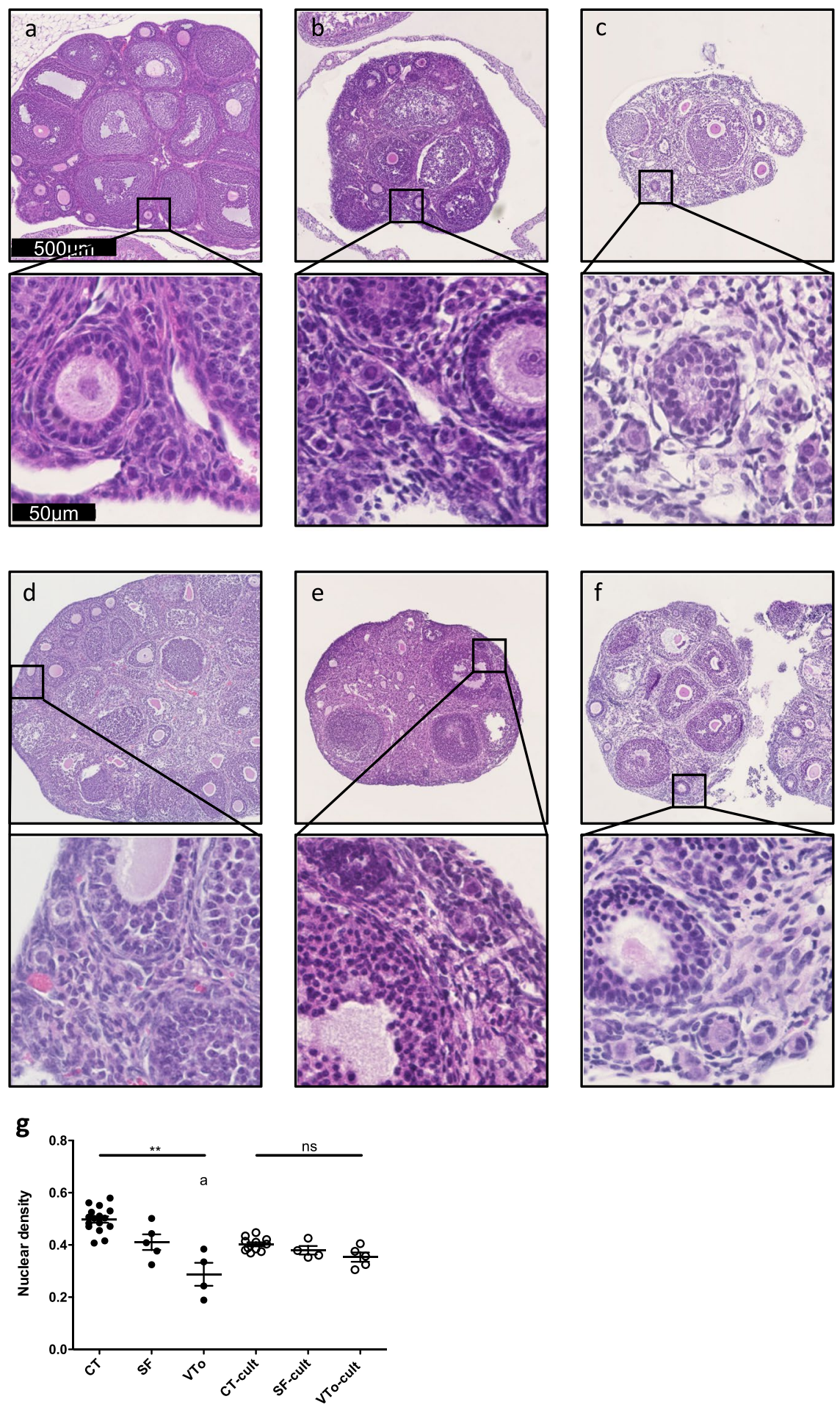

Figure 2. Morphological analysis. Representative images of the haematoxylin \& eosin staining of ovaries from the different groups before (a-c) and after $4 \mathrm{~h}$ of culture $(\mathbf{d}-\mathbf{f})$. Fresh-(CT) (a,d), slow frozen/thawed (SF) $(\mathbf{b}, \mathbf{e})$ and open vitrified/warmed ovaries (VTo) (c,f). (g) Computer-assisted quantification of nuclear density $($ mean $\pm S E M) . n=4-16$ ovaries per group. ns: non-significant, $* * \mathrm{p} \leq 0.01$, a different from CT.

VT is a simple, effective and widely used method for the cryopreservation of oocytes and embryos, taking the place of traditional SF in assisted reproductive technology ${ }^{29,40-42}$. The associated survival rates of oocytes and embryos after the freezing-thawing procedure are similar to those of SF methods ${ }^{20}$. Although oocyte freezing is now mostly performed with VT, there is still controversy regarding the use of SF or VT for ovarian tissue cryopreservation.

In the first part of our study, cryoinjury damage due to SF versus VT was examined in vitro. Immediately after freezing/thawing, the global morphology of the SF ovaries was similar to that of the fresh ovaries, and these 


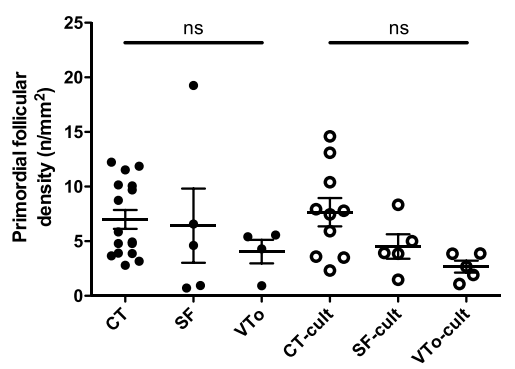

b

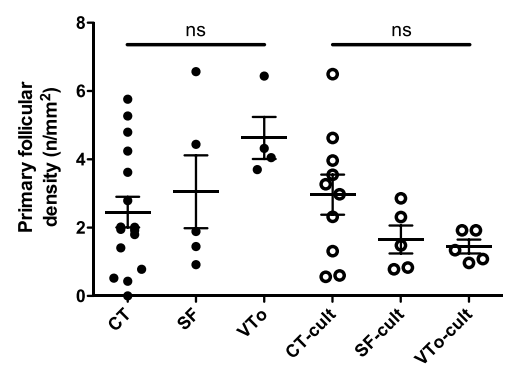

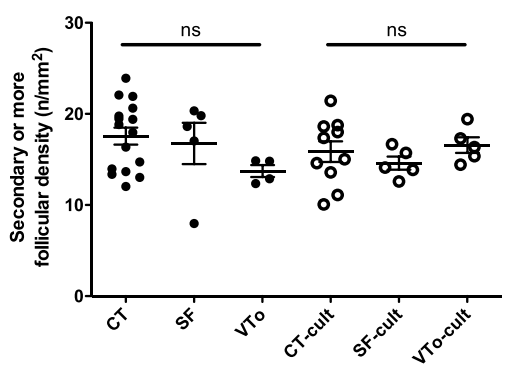

Figure 3. Follicular density analysis. Number/square millimetre of primordial (a), primary (b) or secondary or more follicles $(\mathrm{c})$ (mean $\pm \mathrm{SEM}) . \mathrm{n}=4-16$ ovaries per group. CT: control/fresh ovaries; SF: slow frozen/thawed ovaries, VTo: open vitrified/warmed ovaries, cult: ex vivo culture during 4 hours. ns: non-significant.
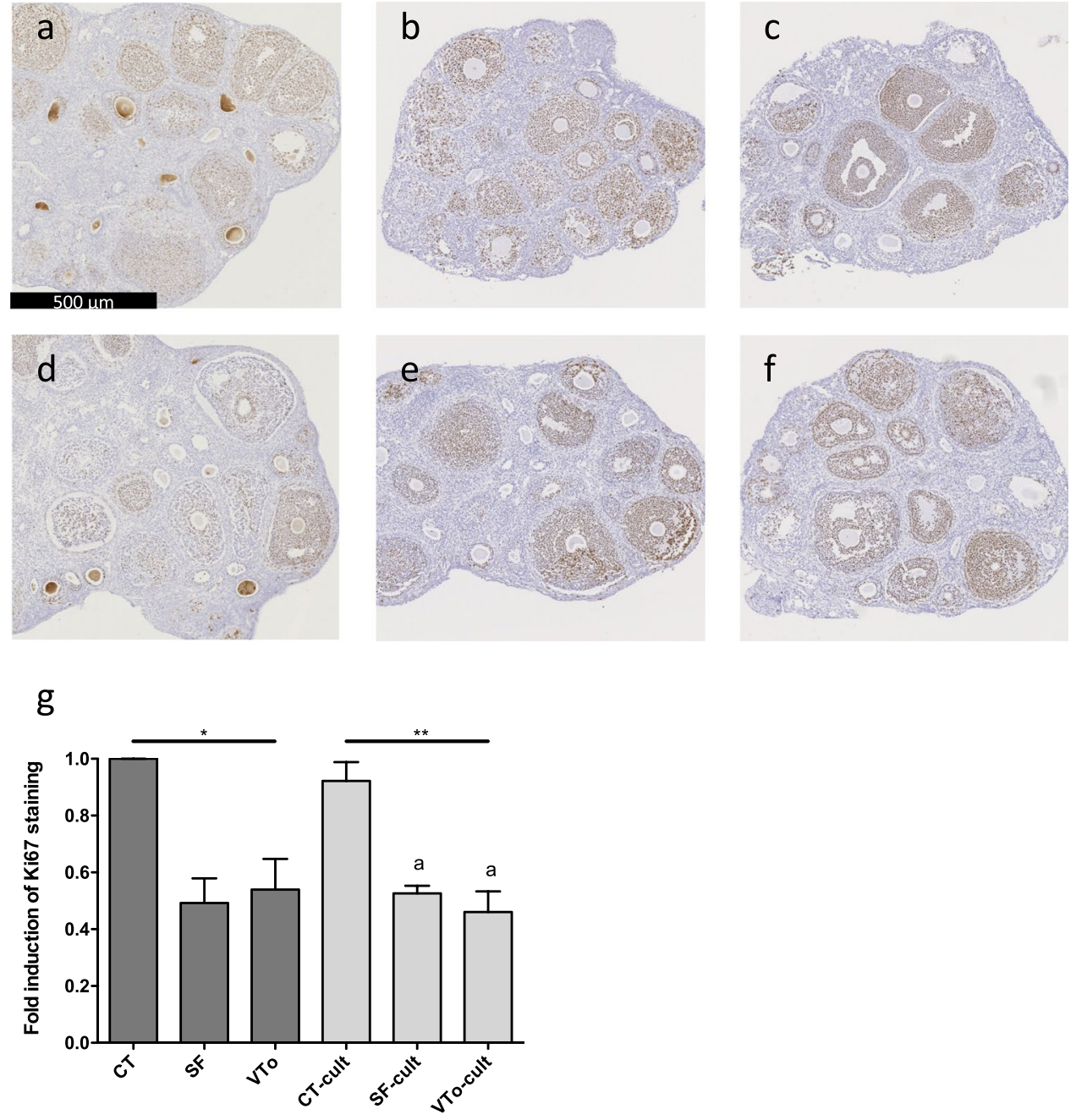

Figure 4. Proliferation analysis with representative illustration of Ki67 immunostaining for CT (a,d), SF $(\mathbf{b}, \mathbf{e})$ and VTo $(\mathbf{c}, \mathbf{f})$ ovaries cultured $(\mathbf{d}-\mathbf{f})$ or not $(\mathbf{a}-\mathbf{c})$ for 4 hours. (g) Computer-assisted quantification of Ki67 immunostaining (mean \pm SEM). $n=4-16$ ovaries per group. CT: control/fresh ovaries; SF: slow frozen/ thawed ovaries, VTo: open vitrified/warmed ovaries, cult: ex vivo culture during 4 hours. ${ }^{*} \mathrm{p} \leq 0.05$, $* * \mathrm{p} \leq 0.01$, adifferent from CT-cult.

ovaries were better preserved than the VTo ovaries. Our results are in agreement with those of Fabbri et al. ${ }^{43}$, although several other studies have revealed a better stromal cell ultrastructure after VT than after SF $20,22,44$. The results concerning follicular morphology after cryopreservation are not always consistent. For example, in Isachenko's study, cryopreservation did not alter follicular morphology ${ }^{45}$, while in several other studies, both 

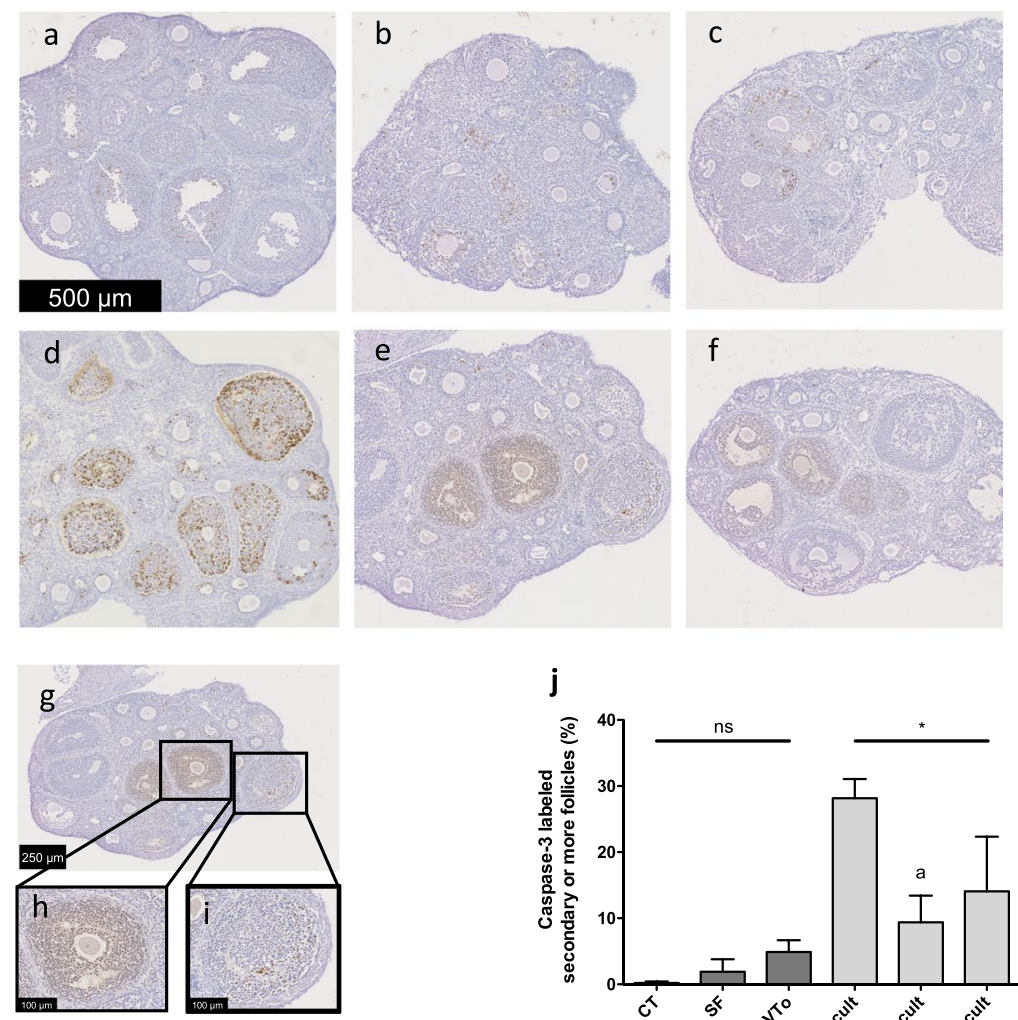

j

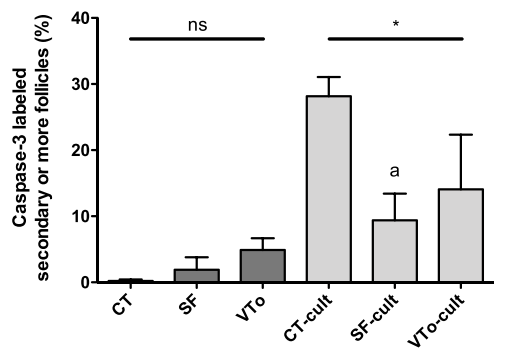

k

I
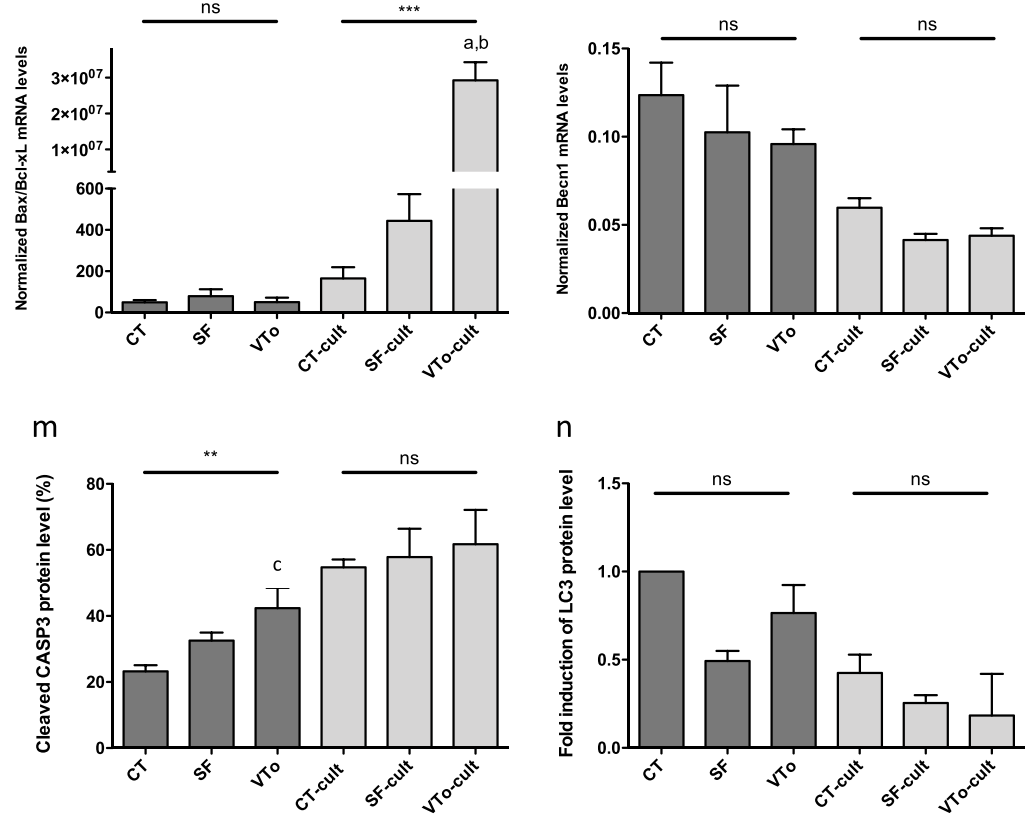

Figure 5. Molecular analysis with representative images of active caspase-3 immunostaining of CT (a,d), SF $(\mathbf{b}, \mathbf{e})$ and VTo $(\mathbf{c}, \mathbf{f})$ ovaries cultured $(\mathbf{d}-\mathbf{f})$ or not $(\mathbf{a}-\mathbf{c})$ for 4 hours. Illustration of labelled antral follicles $(\mathbf{g})$ with more (h) or less (i) than $30 \%$ of active caspase-3 positive granulosa cells. (j) Computer-assisted quantification of active caspase-3 immunostaining. (k) Bax/Bcl-xl mRNA ratios and (1) Becn 1 mRNA levels in the different groups. (m) Western blot quantification of cleaved caspase-3 and (n) LC3 protein level in the different groups. Results are expressed as means \pm SEM. $\mathrm{n}=4-16$ for $(\mathbf{a}-\mathbf{j}) ; \mathrm{n}=9-22$ for $(\mathbf{k}, \mathbf{l}) ; \mathrm{n}=5-16$ for $\mathrm{m}$ and $\mathrm{n}$ per group. CT: control/fresh ovaries; SF: slow frozen/thawed ovaries, VTo: vitrified/warmed ovaries, cult: ex vivo culture

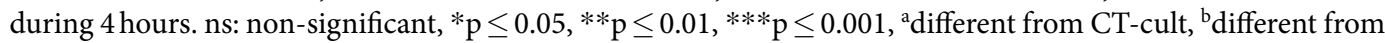
SF-cult and ${ }^{\mathrm{c}}$ different from CT. 
a

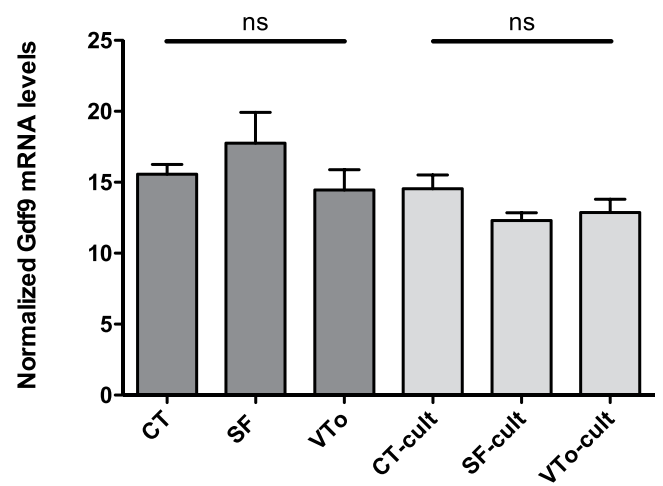

C

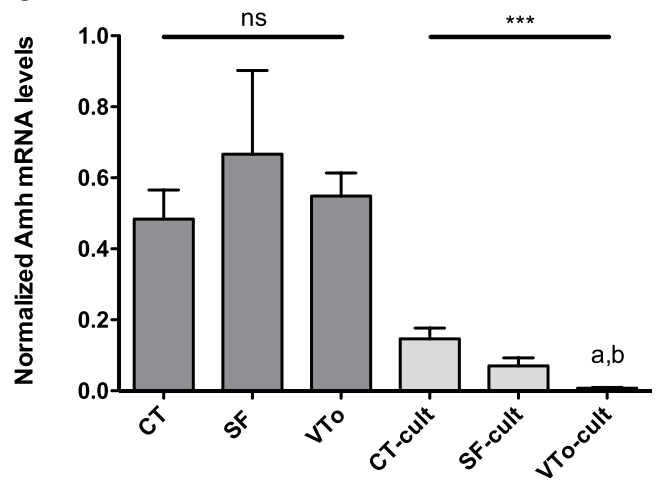

b

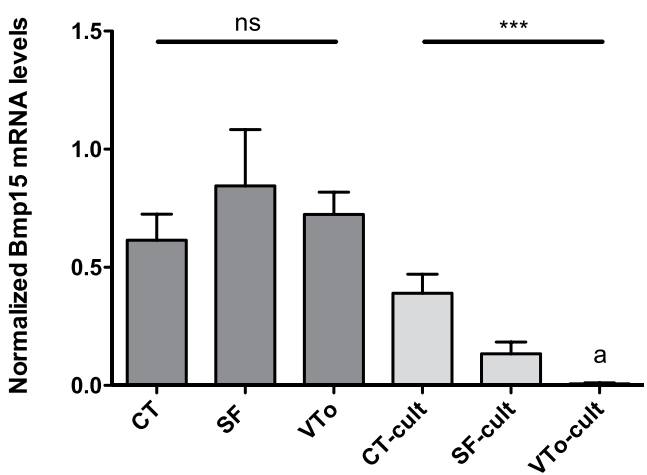

d

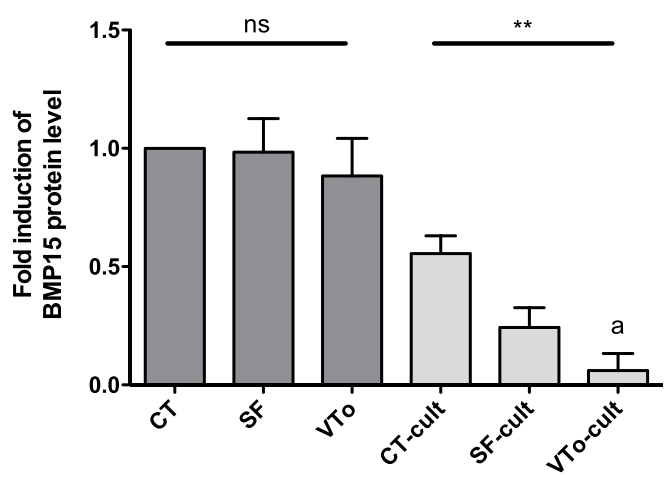

Figure 6. Quantification of the expression level of $G d f 9$ (a), Bmp15 (b), Amh (c) mRNA in the different groups. (d) Western blot quantification of BMP15 protein in the different groups. Results are expressed as means \pm SEM. $n=9-22$ per group for a-c; $n=5-16$ per group for $\mathrm{d}$. CT: control/fresh ovaries; SF: slow frozen/ thawed ovaries, VTo: open vitrified/warmed ovaries, cult: ex vivo culture during 4 hours. ns: non-significant,

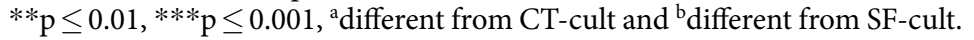

\begin{tabular}{|l|l|l|l|l|l|}
\hline & CT* & SF & VTo & VTc & p value \\
\hline Number of females & 5 & 22 & 11 & 11 & NA \\
\hline $\begin{array}{l}\text { Recovered estrous (3 weeks after } \\
\text { transplantation) }\end{array}$ & NA & $21(95 \%)$ & $10(91 \%)$ & $9(82 \%)$ & $0.4382^{\mathrm{a}}$ \\
\hline $\begin{array}{l}\text { Pregnant mice }(20 \text { weeks after } \\
\text { transplantation) }\end{array}$ & $5(100 \%)$ & $15(68 \%)$ & $7(63 \%)$ & $0(0 \%)^{\mathrm{c}}$ & $0.0002^{\mathrm{a}}$ \\
\hline \multirow{3}{*}{$\begin{array}{l}\text { Number of pregnancies }{ }^{\mathrm{d}}(0,1,2,3=\text { mice } \\
\text { that were never or } 1,2 \text { or } 3 \text { times pregnant) }\end{array}$} & $0: 0(0 \%)$ & $0: 7(32 \%)$ & $0: 4(36 \%)$ & $0: 11$ & $(100 \%)$ \\
\cline { 2 - 5 } & $1: 2(40 \%)$ & $1: 3(14 \%)$ & $1: 6(55 \%)$ & $1: 0(0 \%)$ & \multirow{2}{*}{$0.0005^{\mathrm{a}}$} \\
\cline { 2 - 5 } & $2: 2(40 \%)$ & $2: 9(41 \%)$ & $2: 1(9 \%)$ & $2: 0(0 \%)$ & \\
\cline { 2 - 5 } & $3: 1(20 \%)$ & $3: 3(14 \%)$ & $3: 0(0 \%)$ & $3: 0(0 \%)$ & \\
\hline Litter size (mean \pm SEM) & $3.75 \pm 0.59$ & $3.7 \pm 0.51$ & $2.8 \pm 0.86$ & NA & $0.6089^{\mathrm{b}}$ \\
\hline Surviving litters & $3 / 9(33.3 \%)$ & $14 / 30(47 \%)$ & $1 / 8(12.5 \%)$ & NA & $0.1983^{\mathrm{a}}$ \\
\hline
\end{tabular}

Table 3. Fecundity of females without (CT) or after auto-transplantation with SF or VT ovaries examined after natural mating. *Females were unilaterally ovariectomized at the same time than the others, daily treated with vehicle, sham operated at the day of the auto-transplantation and paired with $\mathrm{C} 57 \mathrm{Bl} / 6$ males in parallel with auto-transplanted females; NA: not applicable; ${ }^{a} \mathrm{Chi}$-square test; ${ }^{\mathrm{b}}$ Kruskal-Wallis test with post hoc analysis (see materials and methods); ${ }^{c} V T c$ versus all groups $(p<0.001) ;{ }^{d} V T c$ versus all groups $(p<0.001)$.

$\mathrm{SF}^{46}$ and VT had less damage in terms of follicle morphology ${ }^{44}$. Several reasons for such divergent results could be the heterogeneity of follicle abundance and distribution, inconsistent tissue size and the different types and concentrations of cryoprotectants. Furthermore, morphological analyses performed just after cryopreservation and thawing could not truly reflect all the potential damage done by the procedure ${ }^{47}$. Therefore, we analysed and quantified follicles after in vitro culture. No differences were observed in the follicular density between groups in agreement with another recent study with ewe ovarian cortex ${ }^{48}$. However, active caspase- 3 was also mostly associated with secondary follicles. These results confirm the findings of previous studies on the human ovarian cortex, in which only granulosa cells associated with antral follicles from cryopreserved ovaries (SF and VT) were 
$\mathrm{CT}$

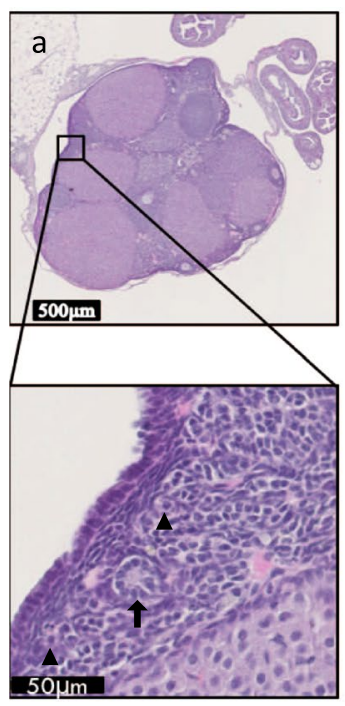

SF (3x preg.)

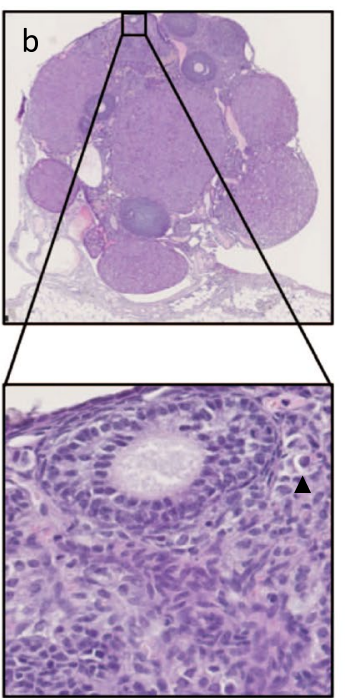

SF (0x preg.)

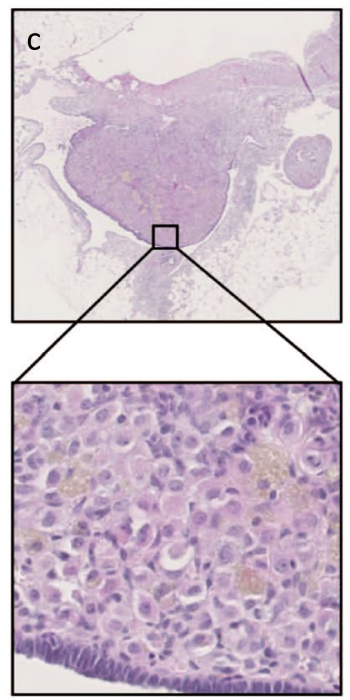

VTo (1x preg.)

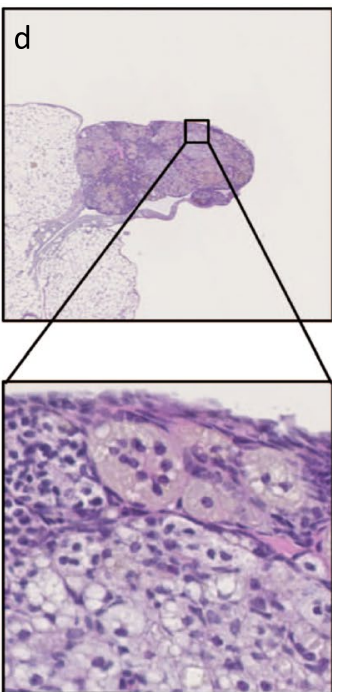

Figure 7. Representative images after H\&E staining of ovaries after the sacrifice. (a) Control ovary; (b) SFovary-auto-transplanted mice that gave birth three times; (c) SF-ovary-auto-transplanted mice that was never pregnant; (d) VTo-ovary-auto-transplanted mice that gave birth once. Arrowheads indicate primordial follicles. Arrow indicates primary follicle.

apoptotic ${ }^{24}$, indicating that growing follicles that are metabolically more active are more sensitive to cryopreservation ${ }^{17}$. By Western blot analysis, the level of active caspase- 3 was higher after VTo than in the CT ovaries. The proto anti-apoptotic mRNA expression ratio $(B a x / B c l-x l)$ increased in all groups after in vitro culture, confirming the previous TUNEL analysis result showing no effect on the apoptosis incidence immediately after the thawing of vitrified ovaries ${ }^{49}$. The fact that the $B a x / B c l-x l$ ratio of the VTo-cult ovaries dramatically increased compared to that of the SF-cult or fresh CT-cult ovaries could indicate that VT changes the susceptibility of the ovaries to apoptotic signals.

Moreover, the analysis of the mRNA levels of $G d f 9$, an oocyte-derived factor involved in folliculogenesis, showed that the levels were similar between all groups. On the other hand, the Bmp15 and Amh mRNA levels were highly impacted by cryopreservation and culture, with a highly significant decrease in the mRNA levels of both genes after the in vitro culture of SF or VTo ovaries, as previously described ${ }^{50}$. A similar study with human ovarian tissue also found that the VT ovaries produced less AMH in vitro than the CT and SF ovaries ${ }^{51}$.

Because most cryopreservation-associated damage can only be detected later, the transplantation of SF or VT ovaries to restore the fertility of young mice with induced premature ovarian failure ${ }^{34}$ may be the best way to evaluate the developmental potential of the ovary after warming, as previously suggested ${ }^{23}$. In our study, we chose to use the chemically induced ovarian failure model to better represent the human clinical condition. Indeed, the injection of VCD directly targets the pool of primordial and primary follicles of the ovary. Moreover, VCD does not have toxic effects on non-ovarian tissues ${ }^{52}$. Here, unilateral ovariectomy was performed before VCD injection, allowing orthotopic auto-transplantation in the follicle-depleted ovary. This model offered the advantage of mimicking the clinical situation for women facing premature ovarian failure after the treatment of their cancers and for whom ovarian tissue cryopreservation was performed before therapy.

There is no consensus on the optimal VT protocol, and in our in vitro study, only one protocol and system were chosen ${ }^{30}$. Notably, from a physical point of view, VT performs with the open system with a direct exposure to liquid nitrogen in a virtually absent volume of medium represents the ideal procedure ${ }^{53}$. However, the risk of contamination with pathogens during the VT procedure or cross-contamination during long-term storage with open system may increase. To overcome such risks, several closed systems have been developed. Because of the thermal insulation of samples in closed VT devices, a decreased cooling rate relative to that of open VT systems could lead to ice crystal formation, resulting in cell death or reduced developmental capacity. One limit of our study is, that we used the same cryopreservation medium for both VT procedures (open and closed). Furthermore, the warming procedure was performed at $37^{\circ} \mathrm{C}$ for both VT procedures. The first step of cryoprotectant unloading was performed at $37^{\circ} \mathrm{C}$ for both VT methods as described by others ${ }^{32,54-56}$. Since there is no consensus for tissue warming after VT, the next steps were also performed at $37^{\circ} \mathrm{C}$. Anyway, to further improve the ovarian VT protocol, warming could be done at room temperature.

In the second part of this study, the in vivo results showed that after auto-transplantation with all types of cryopreserved ovaries (SF, VTo or VTc), most of the mice recovered their oestrous cycles. However, only those transplanted with SF or VTo ovaries became pregnant during the next 20 weeks after grafting. Moreover, the litter size tended to be higher in the SF-transplanted group than in the VTo group ( $3.7 \pm 0.51$ versus $2.8 \pm 0.86)$. Our results partially confirm those of Chen et al., who developed a VT method followed by allogeneic orthotopic transplantation ${ }^{57}$. One striking difference with this study resides in the composition of cryopreservation media. 
Some live births have also been described after the VT and orthotopic allografting of 10-day-old green fluorescent protein (GFP)-transgenic mouse ovaries ${ }^{58}$. However, the number of GFP-positive pups born by natural mating was lower in the graft ovary group than in the CT group, leading to similar results to our own.

We also noticed that the number of surviving litters was different between the mice grafted with SF ovaries and those grafted with VTo ovaries (47\% versus $12.5 \%$ ). In conventional breeding, the pup mortality rates of laboratory mice are commonly high in the first litter, and the inability of primiparous females to care appropriately for their offspring has been reported ${ }^{59}$. The pup mortality rate of a litter depends on the mouse strain, with $\mathrm{C} 57 \mathrm{Bl} / 6$ mothers having significantly higher pup mortality than DBA/2 J mothers, with more pup deaths in the first than in the second litter and with most deaths occurring within the first 3 days after parturition ${ }^{60}$.

Histological analyses of ovaries that were recovered 8 months after grafting showed that SF ovaries from mice that were previously pregnant displayed similar follicular development and corpora lutea formation to the CT ovaries, whereas the both VTo ovaries and SF ovaries recovered from the mice that were never pregnant displayed only a few corpora lutea and no more primordial or growing follicles.

\section{Conclusion}

Our in vitro results indicate that differences between SF and VTo ovaries immediately after thawing/warming are not evident by histo-morphological analysis of cryopreserved ovarian tissue. However, immunohistochemical and RT-qPCR analyses for apoptosis and specific follicular proteins are altered after culture, mostly in VTo ovaries compared to SF ovaries. In addition, auto-transplantation of SF ovaries, as well as VTo ovaries, fully restores mouse fertility and achieved the highest number of pregnancies. Even though auto-transplantation with VTc ovaries restored ovarian cycles, no pregnancies were achieved.

Received: 23 June 2019; Accepted: 14 November 2019;

Published online: 23 December 2019

\section{References}

1. Meirow, D., Biederman, H., Anderson, R. A. \& Wallace, W. H. Toxicity of chemotherapy and radiation on female reproduction. Clin. Obstet. Gynecol. 53, 727-739, https://doi.org/10.1097/GRF.0b013e3181f96b54 (2010).

2. Demeestere, I., Moffa, F., Peccatori, F., Poirot, C. \& Shalom-Paz, E. Multiple approaches for individualized fertility protective therapy in cancer patients. Obstet. Gynecol. Int. 2012, 961232, https://doi.org/10.1155/2012/961232 (2012).

3. Fisch, B. \& Abir, R. Female fertility preservation: past, present and future. Reproduction 156, F11-F27, https://doi.org/10.1530/REP17-0483 (2018)

4. Donnez, J. \& Dolmans, M. M. Fertility Preservation in Women. N. Engl. J. Med. 377, 1657-1665, https://doi.org/10.1056/ NEJMra1614676 (2017)

5. Poirot, C. et al. Induction of puberty by autograft of cryopreserved ovarian tissue. Lancet 379, 588, https://doi.org/10.1016/S01406736(11)61781-9 (2012).

6. Ernst, E., Bergholdt, S., Jorgensen, J. S. \& Andersen, C. Y. The first woman to give birth to two children following transplantation of frozen/thawed ovarian tissue. Hum. Reprod. 25, 1280-1281, https://doi.org/10.1093/humrep/deq.033 (2010).

7. Jensen, A. K. et al. 86 successful births and 9 ongoing pregnancies worldwide in women transplanted with frozen-thawed ovarian tissue: focus on birth and perinatal outcome in 40 of these children. J. Assist. Reprod. Genet. 34, 325-336, https://doi.org/10.1007/ s10815-016-0843-9 (2017).

8. Matthews, S. J., Picton, H., Ernst, E. \& Andersen, C. Y. Successful pregnancy in a woman previously suffering from beta-thalassemia following transplantation of ovarian tissue cryopreserved before puberty. Minerva Ginecol. 70, 432-435, https://doi.org/10.23736/ S0026-4784.18.04240-5 (2018).

9. Donnez, J. \& Dolmans, M. M. Ovarian cortex transplantation: 60 reported live births brings the success and worldwide expansion of the technique towards routine clinical practice. J. Assist. Reprod. Genet. 32, 1167-1170, https://doi.org/10.1007/s10815-015-05449 (2015).

10. Van der Ven, H. et al. Ninety-five orthotopic transplantations in 74 women of ovarian tissue after cytotoxic treatment in a fertility preservation network: tissue activity, pregnancy and delivery rates. Hum. Reprod. 31, 2031-2041, https://doi.org/10.1093/humrep/ dew165 (2016).

11. Practice Committee of American Society for Reproductive. M. Ovarian tissue cryopreservation: a committee opinion. Fertil. Steril. 101, 1237-1243, https://doi.org/10.1016/j.fertnstert.2014.02.052 (2014).

12. Silber, S. J. et al. Cryopreservation and transplantation of ovarian tissue: results from one center in the USA. J. Assist. Reprod. Genet. 35, https://doi.org/10.1007/s10815-018-1315-1 (2018).

13. Kawamura, K. et al. Hippo signaling disruption and Akt stimulation of ovarian follicles for infertility treatment. Proc. Natl. Acad. Sci. USA 110, 17474-17479, https://doi.org/10.1073/pnas.1312830110 (2013).

14. Suzuki, N. et al. Successful fertility preservation following ovarian tissue vitrification in patients with primary ovarian insufficiency. Hum. Reprod. 30, 608-615, https://doi.org/10.1093/humrep/deu353 (2015).

15. Amorim, C. A., Curaba, M., Van Langendonckt, A., Dolmans, M. M. \& Donnez, J. Vitrification as an alternative means of cryopreserving ovarian tissue. Reproductive biomedicine online 23, 160-186, https://doi.org/10.1016/j.rbmo.2011.04.005 (2011).

16. Courbiere, B., Baudot, A., Mazoyer, C., Salle, B. \& Lornage, J. Vitrification: a future technique for ovarian cryopreservation? Physical basis of cryobiology, advantages and limits. Gynecol. Obstet. Fertil. 37, 803-813 (2009).

17. Salama, M. \& Woodruff, T. New advances in ovarian autotransplantation to restore fertility in cancer patients. Cancer Metastasis Rev. 34, 807-822, https://doi.org/10.1007/s10555-015-9600-2 (2015).

18. Cobo, A. et al. Vitrification: an effective new approach to oocyte banking and preserving fertility in cancer patients. Clin. Transl. Oncol. 10, 268-273 (2008).

19. Cobo, A. et al. Oocyte vitrification as an efficient option for elective fertility preservation. Fertil. Steril. 105, 755-764 e758, https:// doi.org/10.1016/j.fertnstert.2015.11.027 (2016).

20. Keros, V. et al. Vitrification versus controlled-rate freezing in cryopreservation of human ovarian tissue. Hum.Reprod. 24, 1670-1683 (2009).

21. Chang, H. J. et al. Optimal condition of vitrification method for cryopreservation of human ovarian cortical tissues. J. Obstet. Gynaecol. Res. 37, 1092-1101, https://doi.org/10.1111/j.1447-0756.2010.01496.x (2011).

22. Fabbri, R. et al. Good preservation of stromal cells and no apoptosis in human ovarian tissue after vitrification. BioMed research international 2014, 673537, https://doi.org/10.1155/2014/673537 (2014).

23. Abir, R. et al. Attempts to improve human ovarian transplantation outcomes of needle-immersed vitrification and slow-freezing by host and graft treatments. J. Assist. Reprod. Genet. 34, 633-644, https://doi.org/10.1007/s10815-017-0884-8 (2017). 
24. Herraiz, S. et al. Improving ovarian tissue cryopreservation for oncologic patients: slow freezing versus vitrification, effect of different procedures and devices. Fertil. Steril. 101, 775-784.e771, https://doi.org/10.1016/j.fertnstert.2013.11.016 (2014).

25. Lee, S. et al. Comparison between Slow Freezing and Vitrification for Human Ovarian Tissue Cryopreservation and Xenotransplantation. International journal of molecular sciences 20, 3346, https://doi.org/10.3390/ijms20133346 (2019).

26. Bielanski, A. A review of the risk of contamination of semen and embryos during cryopreservation and measures to limit crosscontamination during banking to prevent disease transmission in ET practices. Theriogenology 77, 467-482, https://doi. org/10.1016/j.theriogenology.2011.07.043 (2012).

27. Larman, M. G., Hashimoto, S., Morimoto, Y. \& Gardner, D. K. Cryopreservation in ART and concerns with contamination during cryobanking. Reprod. Med. Biol. 13, 107-117, https://doi.org/10.1007/s12522-014-0176-2 (2014).

28. Rall, W. F. \& Fahy, G. M. Ice-free cryopreservation of mouse embryos at $-196^{\circ} \mathrm{C}$ by vitrification. Nature 313,573 , https://doi. org/10.1038/313573a0 (1985).

29. Vajta, G., Rienzi, L. \& Ubaldi, F. M. Open versus closed systems for vitrification of human oocytes and embryos. Reproductive biomedicine online 30, 325-333, https://doi.org/10.1016/j.rbmo.2014.12.012 (2015).

30. Youm, H. W. et al. Optimal vitrification protocol for mouse ovarian tissue cryopreservation: effect of cryoprotective agents and in vitro culture on vitrified-warmed ovarian tissue survival. Hum. Reprod. 29, 720-730, https://doi.org/10.1093/humrep/det449 (2014).

31. Gosden, R. G., Baird, D. T., Wade, J. C. \& Webb, R. Restoration of fertility to oophorectomized sheep by ovarian autografts stored at -196 degrees C. Hum. Reprod. 9, 597-603 (1994).

32. Dalman, A. et al. Slow freezing versus vitrification technique for human ovarian tissue cryopreservation: An evaluation of histological changes, WNT signaling pathway and apoptotic genes expression. Cryobiology 79, 29-36, https://doi.org/10.1016/j. cryobiol.2017.09.007 (2017).

33. Myers, M., Britt, K. L., Wreford, N. G., Ebling, F. J. \& Kerr, J. B. Methods for quantifying follicular numbers within the mouse ovary. Reproduction 127, 569-580, https://doi.org/10.1530/rep.1.00095 (2004).

34. Haas, J. R., Christian, P. J. \& Hoyer, P. B. Effects of impending ovarian failure induced by 4 -vinylcyclohexene diepoxide on fertility in C57BL/6 female mice. Comp. Med. 57, 443-449 (2007).

35. Byers, S. L., Wiles, M. V., Dunn, S. L. \& Taft, R. A. Mouse estrous cycle identification tool and images. PLoS One 7, e35538, https:// doi.org/10.1371/journal.pone.0035538 (2012).

36. Salehnia, M., Sheikhi, M., Pourbeiranvand, S. \& Lundqvist, M. Apoptosis of human ovarian tissue is not increased by either vitrification or rapid cooling. Reproductive biomedicine online 25, 492-499, https://doi.org/10.1016/j.rbmo.2012.07.021 (2012).

37. Sheikhi, M., Hultenby, K., Niklasson, B., Lundqvist, M. \& Hovatta, O. Clinical grade vitrification of human ovarian tissue: an ultrastructural analysis of follicles and stroma in vitrified tissue. Hum. Reprod. 26, 594-603, https://doi.org/10.1093/humrep/ deq.357 (2011).

38. Pegg, D. E. Principles of cryopreservation. Methods Mol. Biol. 368, 39-57, https://doi.org/10.1007/978-1-59745-362-2_3 (2007).

39. Jacobsen, I. A. \& Pegg, D. E. Cryopreservation of organs: a review. Cryobiology 21, 377-384, https://doi.org/10.1016/00112240(84)90076-2 (1984).

40. Edgar, D. H. \& Gook, D. A. A critical appraisal of cryopreservation (slow cooling versus vitrification) of human oocytes and embryos. Hum. Reprod. Update 18, 536-554, https://doi.org/10.1093/humupd/dms016 (2012).

41. Li, Z., Wang, Y. A., Ledger, W., Edgar, D. H. \& Sullivan, E. A. Clinical outcomes following cryopreservation of blastocysts by vitrification or slow freezing: a population-based cohort study. Hum. Reprod. 29, 2794-2801, https://doi.org/10.1093/humrep/ deu246 (2014).

42. Cai, H. et al. Open versus closed vitrification system of human oocytes and embryos: a systematic review and meta-analysis of embryologic and clinical outcomes. Reprod. Biol. Endocrinol. 16, 123, https://doi.org/10.1186/s12958-018-0440-0 (2018).

43. Fabbri, R. et al. Morphological, ultrastructural and functional imaging of frozen/thawed and vitrified/warmed human ovarian tissue retrieved from oncological patients. Hum. Reprod. 31, 1838-1849, https://doi.org/10.1093/humrep/dew134 (2016).

44. Ting, A. Y., Yeoman, R. R., Lawson, M. S. \& Zelinski, M. B. In vitro development of secondary follicles from cryopreserved rhesus macaque ovarian tissue after slow-rate freeze or vitrification. Hum. Reprod. 26, 2461-2472, https://doi.org/10.1093/humrep/der196 (2011).

45. Isachenko, V. et al. Human ovarian tissue vitrification versus conventional freezing: morphological, endocrinological, and molecular biological evaluation. Reproduction 138, 319-327, https://doi.org/10.1530/REP-09-0039 (2009).

46. Sanfilippo, S. et al. Quality and functionality of human ovarian tissue after cryopreservation using an original slow freezing procedure. J. Assist. Reprod. Genet. 30, 25-34, https://doi.org/10.1007/s10815-012-9917-5 (2013).

47. Klocke, S., Bundgen, N., Koster, F., Eichenlaub-Ritter, U. \& Griesinger, G. Slow-freezing versus vitrification for human ovarian tissue cryopreservation. Arch. Gynecol. Obstet. 291, 419-426, https://doi.org/10.1007/s00404-014-3390-6 (2015).

48. Locatelli, Y. et al. In vitro survival of follicles in prepubertal ewe ovarian cortex cryopreserved by slow freezing or non-equilibrium vitrification. J. Assist. Reprod. Genet. https://doi.org/10.1007/s10815-019-01532-8 (2019).

49. Mazoochi, T., Salehnia, M., Valojerdi, M. R. \& Mowla, S. J. Morphologic, ultrastructural, and biochemical identification of apoptosis in vitrified-warmed mouse ovarian tissue. Fertil. Steril. 90, 1480-1486, https://doi.org/10.1016/j.fertnstert.2007.07.1384 (2008).

50. Cierniewska-Cieslak, A. et al. Identification and characterization of two cation binding sites in the integrin beta 3 subunit. J. Biol. Chem. 277, 11126-11134, https://doi.org/10.1074/jbc.M112388200 (2002).

51. Oktem, O. et al. Vitrified human ovaries have fewer primordial follicles and produce less antimullerian hormone than slow-frozen ovaries. Fertil. Steril. 95, 2661-2664 e2661, https://doi.org/10.1016/j.fertnstert.2010.12.057 (2011).

52. Kappeler, C. J. \& Hoyer, P. B. 4-Vinylcyclohexene Diepoxide: A Model Chemical for Ovotoxicity. Syst. Biol. Reprod. Med. 58, 57-62, https://doi.org/10.3109/19396368.2011.648820 (2012).

53. Kuwayama, M., Vajta, G., Ieda, S. \& Kato, O. Comparison of open and closed methods for vitrification of human embryos and the elimination of potential contamination. Reproductive biomedicine online 11, 608-614 (2005).

54. Kagawa, N., Silber, S. \& Kuwayama, M. Successful vitrification of bovine and human ovarian tissue. Reproductive biomedicine online 18, 568-577 (2009).

55. Wang, Y., Xiao, Z., Li, L., Fan, W. \& Li, S. W. Novel needle immersed vitrification: a practical and convenient method with potential advantages in mouse and human ovarian tissue cryopreservation. Hum. Reprod. 23, 2256-2265, https://doi.org/10.1093/humrep/ den255 (2008).

56. Kagawa, N. et al. Production of the first offspring from oocytes derived from fresh and cryopreserved pre-antral follicles of adult mice. Reproductive biomedicine online 14, 693-699, https://doi.org/10.1016/s1472-6483(10)60670-0 (2007).

57. Chen, S.-U. et al. Novel direct cover vitrification for cryopreservation of ovarian tissues increases follicle viability and pregnancy capability in mice. Hum. Reprod. 21, 2794-2800, https://doi.org/10.1093/humrep/del210 (2006).

58. Migishima, F. et al. Successful Cryopreservation of Mouse Ovaries by Vitrification. Biol. Reprod. 68, 881-887, https://doi. org/10.1095/biolreprod.102.007948 (2003)

59. Nowak, R., Porter, R. H., Levy, F., Orgeur, P. \& Schaal, B. Role of mother-young interactions in the survival of offspring in domestic mammals. Rev. Reprod. 5, 153-163 (2000).

60. Brown, R. E., Mathieson, W. B., Stapleton, J. \& Neumann, P. E. Maternal behavior in female C57BL/6J and DBA/2J inbred mice. Physiol. Behav. 67, 599-605 (1999). 


\section{Acknowledgements}

The authors acknowledge Isabelle Dasoul, Emilie Feyereisen, Erika Kondarowski and Nathalie Lefin for their excellent technical assistance. The authors also thank Silvia Blacher for statistical analysis and Marie-Caroline Masereel. This work was supported by grants from the Fonds de la Recherche Scientifique - FNRS (F.R.S.-FNRS, Belgium), the Foundation against Cancer (foundation of public interest, Belgium), the Fonds spéciaux de la Recherche (University of Liège), the Centre Anticancéreux près l'Université de Liège, the Fonds Léon Fredericq (University of Liège).

\section{Author contributions}

C.T., M.F. and M.A. performed the experimental work and prepared all figures. M.F. and M.N. conceived and designed the study. C.M. conceived and designed the study, interpreted data and wrote the manuscript. All authors read and approved the final manuscript.

\section{Competing interests}

The authors declare no competing interests.

\section{Additional information}

Supplementary information is available for this paper at https://doi.org/10.1038/s41598-019-56182-8.

Correspondence and requests for materials should be addressed to C.M.

Reprints and permissions information is available at www.nature.com/reprints.

Publisher's note Springer Nature remains neutral with regard to jurisdictional claims in published maps and institutional affiliations.

Open Access This article is licensed under a Creative Commons Attribution 4.0 International License, which permits use, sharing, adaptation, distribution and reproduction in any medium or format, as long as you give appropriate credit to the original author(s) and the source, provide a link to the Creative Commons license, and indicate if changes were made. The images or other third party material in this article are included in the article's Creative Commons license, unless indicated otherwise in a credit line to the material. If material is not included in the article's Creative Commons license and your intended use is not permitted by statutory regulation or exceeds the permitted use, you will need to obtain permission directly from the copyright holder. To view a copy of this license, visit http://creativecommons.org/licenses/by/4.0/.

(C) The Author(s) 2019 